BENTHAM OPEN
CrossMark
Content list available at: www.benthamopen.com/TODENTJ/
DOI: $10.2174 / 1874210601812011036,2018,12,1036-1042$

RESEARCH ARTICLE

\title{
Immunophenotyping Oral Amyloidosis for the Precise Identification of the Biochemical Forms: A Retrospective Study
}

\author{
Nada Binmadi ${ }^{1, *}$, Chidan Intapa ${ }^{2}$, Risa Chaisuparat ${ }^{3}$, Sara Akeel $^{1}$, Amal Sindi $^{1}$ and Timothy Meiller ${ }^{4}$ \\ ${ }^{I}$ Department of Oral Diagnostic Sciences, Faculty of Dentistry, King Abdulaziz University, Jeddah, Saudi Arabia \\ ${ }^{2}$ Department of Oral Diagnosis, Faculty of Dentistry, Naresuan University, Muang, Phitsanulok, Thailand \\ ${ }^{3}$ Department of Oral Pathology, Faculty of Dentistry, Chulalongkorn University, Bangkok, Thailand \\ ${ }^{4}$ Department of Oncology and Diagnostic Sciences, School of Dentistry, University of Maryland/ Marlene and Stewart \\ Greenebaum Comprehensive Cancer Center, University of Maryland Medical System, Baltimore, MD, USA
}

Received: August 10, 2018

Revised: October 26, 2018

Accepted: November 4, 2018

\begin{abstract}
:
Background:

Amyloidosis refers to a group of systemic and localized disorders associated with the accumulation of misfolded protein aggregates called amyloids in different parts of the body. Owing to the existence of multiple forms of amyloids with similar tertiary structures, precise identification of their biochemical form is critical for correct therapy.
\end{abstract}

\section{Objective:}

This retrospective study aimed to determine whether typing of oral amyloid deposits can help diagnose a serious systemic condition in the early phase of the disease

\section{Methods:}

All histopathologically confirmed cases of amyloidosis managed over a 14-year period (January 1, 1997 to December 31, 2011) were retrieved for analysis. Two board-certified oral and maxillofacial pathologists reviewed the histopathological findings of amyloidosis on the basis of its classic Congo red staining characteristics. This was followed by immunohistochemical analysis of biopsy samples using a panel of antibodies specific for different forms of amyloidosis.

Results:

The most common location of amyloidosis was the tongue, and women were more commonly affected than men. The patient age ranged from 11 to 83 years (average 59.3 years). In patient 9, light-chain and pre-albumin (transthyretin) antibodies were related to arthritis and senile amyloidosis, respectively. The biopsy sample of patient 10, who was reported to have multiple myeloma, was positive for light chains and $\beta 2$ microglobulin. All other samples exhibited localized (solitary) amyloidosis.

\section{Conclusion:}

Histological analysis coupled with immunostaining with a panel of specific antibodies might assist in identifying early systemic amyloidosis in patients with localized oral forms of the disease.

Keywords: Amyloidosis, Oral amyloids, Systemic, Localized, Immuno-phenotyping, $\beta-2$ microglobulin.

\footnotetext{
"Address correspondence to this author at the Department of Oral Diagnostic Sciences, Faculty of Dentistry, King Abdulaziz University, PO Box 80209, Jeddah 21589, Saudi Arabia; Tel: 0505699092; E-mail: nmadi@kau.edu.sa
} 


\section{INTRODUCTION}

Amyloidosis is the condition of accumulation of extracellular fibrillar proteins in organs and soft tissues, which can be grouped as a localized or systemic disease. Although amyloids were first identified in the $19^{\text {th }}$ century by Virchow, the etiology and pathological process of amyloidosis have remained unclear. Currently, 30 different types of amyloidosis are known, which occur because of protein misfolding [1]. Amyloidosis is classified on the basis of the type of affected protein and the anatomical location of misfolded-protein deposits. The most frequent type of primary amyloidosis is Immunoglobulin (IGg) light-chain systemic amyloidosis (systemic AL), which is often observed in individuals with multiple myeloma [2,3]. Systemic AL is caused by specific mutations in monoclonal light chains, which form partially folded structures that aggregate into oligomers and subsequently into highly-ordered cross- $\beta$-sheet proteins. Secondary amyloidosis (systemic amyloid A amyloidosis) is caused by chronic inflammatory diseases such as lupus, rheumatoid arthritis, tuberculosis, and inflammatory bowel disease, and it commonly affects the spleen, kidneys, liver, adrenal glands, and lymph nodes [4].

Localized amyloidosis, which is more common than systemic amyloidosis and not associated with mortality [5], includes organ-limited forms, formation of focal amyloid deposits, and senile amyloidosis [6]. Familial or hereditary Amyloidosis (Transthyretin-related Amyloidosis; ATTR) is caused by accumulation of a mutant form of the Transthyretin (TTR) protein in the liver. In the elderly, wild-type TTR can also accumulate in the heart, a condition called senile amyloidosis. Dialysis-related amyloidosis is observed in older adults who have been undergoing dialysis for more than five years; the disease is characterized by the accumulation of $\beta-2$ microglobulin in bones, joints, and tendons [7]. The 25 distinct biochemical forms of amyloids known to date possess similar tertiary $\beta$-pleated-sheet structures, albeit with different chemical compositions [8 - 10]. Correct identification of amyloid forms is critical because treatment strategies vary with the disease type $[5,6]$.

Amyloidosis is generally diagnosed by hematoxylin and eosin staining of biopsy specimens, where amyloids appear as amorphous pink-to-red areas, or by Congo red staining, where they exhibit green birefringence under polarized light. Electron microscopy findings show that all amyloid subtypes are constituted of 7.5 to $10 \mathrm{~nm}$ wide simple, nonbranching, tubular protein strands organized into a network [11]. Recently, several groups have performed immunophenotyping of AL using multiparameter flow cytometry to determine whether detection of abnormal plasmacell clones in bone marrow could be useful for AL diagnosis and prognosis [12 - 15].

Amyloids are usually found in the tongue. When intra-oral amyloidosis is diagnosed, additional examinations are needed to assess the functions of the systemic organs that are usually involved (e.g., the heart, liver, and kidneys) and to exclude underlying plasma-cell disorders. The objective of this retrospective study was to determine whether typing of oral amyloid deposits can be useful for diagnosing a serious systemic condition in the early phase of the disease. The study was conducted in two phases. First, 13 oral biopsy specimens that were conclusively positive for amyloidosis were reviewed to confirm the diagnosis, and relevant clinical data were collected. Next, immunohistochemical staining was performed with a routine antibody panel (against kappa and lambda light chains, ATTR, and amyloid beta-2 microglobulin). The outcomes were additionally analyzed for their relationship with the medical status of the patients, including clinical parameters and follow-up reports.

\section{MATERIALS AND METHODS}

\subsection{Retrospective Review of Cases}

Thirteen biopsy reports from January 1, 1997 to December 31, 2011, that showed diagnosis of amyloidosis from the Department of Oral Pathology at the University of Maryland (Baltimore) were retrieved. For all cases, two boardcertified oral and maxillofacial pathologists (NB and RC) reviewed and confirmed the histopathological findings of amyloidosis on the basis of its classic Congo red staining characteristics. The following clinical information was summarized: Age, sex, location, medical history, and development of systemic or multifocal disease. The correlation between clinical and immunohistochemical findings was analyzed and summarized Table 1. The study protocol was reviewed and approved by the University of Maryland Institutional Review Board (Protocol \#HP-00040308).

Table 1. Immunostaining results and patient medical characteristics.

\begin{tabular}{|c|c|c|c|c|c|}
\hline Case \# & Age & Sex & Location & Positive Antibody & Medical Condition \\
\hline $\mathbf{1}$ & 80 & F & Tongue & - & - \\
\hline $\mathbf{2}$ & - & F & Lip & Kappa $(\kappa)$ & - \\
\hline
\end{tabular}


(Table 1) contd.....

\begin{tabular}{|c|c|c|c|c|c|}
\hline Case \# & Age & Sex & Location & Positive Antibody & Medical Condition \\
\hline $\mathbf{3}$ & - & - & Palate & Lambda $(\lambda)$ & - \\
\hline $\mathbf{4}$ & 46 & $\mathrm{M}$ & Lip & Kappa $(\kappa)$ & - \\
\hline $\mathbf{5}$ & 79 & $\mathrm{~F}$ & Gingiva & Kappa $(\kappa)$ & - \\
\hline $\mathbf{6}$ & 61 & $\mathrm{~F}$ & Buccal Mucosa & $\beta-2-$ microglobulin, pre-albumin & - \\
\hline $\mathbf{7}$ & 58 & $\mathrm{~F}$ & Tongue & Kappa $(\kappa)$ & - \\
\hline $\mathbf{8}$ & 75 & $\mathrm{M}$ & Palate & Lambda $(\lambda)$, pre-albumin & - \\
\hline $\mathbf{9}$ & 83 & $\mathrm{M}$ & Tongue & Kappa $(\kappa), \beta-2-$ microglobulin & Arthritis, senile amyloidosis \\
\hline $\mathbf{1 0}$ & 52 & $\mathrm{~F}$ & Tongue & Lambda $(\lambda)$ & Multiple myeloma \\
\hline $\mathbf{1 1}$ & 66 & $\mathrm{M}$ & Palate & Lambda $(\lambda), \beta-2-$ microglobulin, pre-albumin & - \\
\hline $\mathbf{1 2}$ & 41 & F & Tongue & Kappa $(\kappa)$ & Chronic backache, HIV \\
\hline $\mathbf{1 3}$ & 11 & F & Gingiva & Seizure & \\
\hline
\end{tabular}

M: Male, F: Female

\subsection{Immunohistochemistry}

Fixed paraffin-embedded tissue blocks of 13 patients with amyloidosis were obtained and sectioned. The tissue sections were stained for identifying the amyloid type. The slides were incubated overnight with primary polyclonal antibodies against lambda $(\lambda)$ and kappa ( $\kappa$ ) light chains at a 1:100 dilution (DAKO, Carpenteria, CA, USA), prealbumin (ATTR) antibodies at a 1: 400 dilution, and beta-2 microglobulin antibodies at a 1: 600 dilution at $4^{\circ} \mathrm{C}$ in a humidity chamber.

The slides were then incubated for 1 hour at room temperature with secondary antibodies (1: 500 dilution; Vector Laboratories, Burlingame, CA) in 1\% bovine serum albumin in Phosphate-Buffered Saline (PBS). They were then washed with PBS and incubated at room temperature with the avidin-biotin complex (Vector Stain Elite, ABC kit; Vector Laboratories, Burlingame, CA) for $30 \mathrm{~min}$ or with streptavidin peroxidase (LSAB2 HRP kit; DAKO, Carpenteria, CA, USA) for $10 \mathrm{~min}$. The tissue sections were treated using a DAB peroxidase substrate kit (Vector Laboratories, Burlingame, CA) and then counterstained with hematoxylin.

\section{RESULTS}

Thirteen biopsy reports over a 14-year period that showed diagnosis of amyloidosis were retrieved and reviewed. The corresponding biopsy specimens had been excised from oral tissues with clinically obvious lesions. The specimens had been collected from thirteen patients, including eight women, four men, and one patient of unspecified sex. Five specimens were collected from the tongue, three from the palate, two from the gingiva, two from lips, and one from buccal mucosa. After examining the slides stained with hematoxylin and eosin, tissue segments from these cases were stained with Congo red, upon which the amyloid deposits showed apple-green birefringence under polarized light, (Table 1, (Fig. 1)).
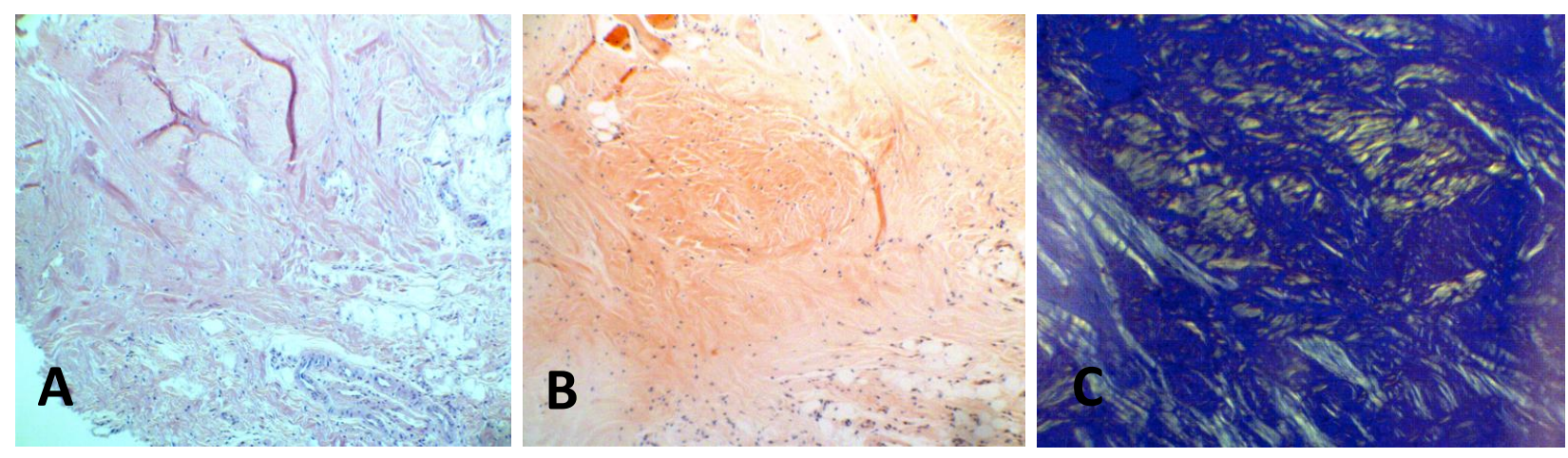

Fig. (1). (A) An incisional biopsy from the dorsal tongue of case number 9 was performed and histological examination showed an eosinophilic amorphous material in the connective tissue beneath the epithelium with a few inflammatory cells. (B) A red homogenous material with cracking artifact was visible in tissue sections stained with Congo red, and (C) The same area showed an apple green birefringence under polarized light. These findings were consistent with the diagnosis of amyloidosis.

The most common location of amyloidosis was the tongue. Women were more commonly affected than men, with an incidence ratio of 2:1. The patient age ranged from 11 to 83 years, with an average age of 59.3 years. In patient 9 
Fig. (2), the positive results of immunostaining with light-chain and pre-albumin (TTR) antibodies were related to arthritis and senile amyloidosis, respectively. The biopsy sample of patient 10, who was reported to have multiple myeloma, was positive for light chains and $\beta-2$ microglobulin. Specimens of all other cases exhibited localized (solitary) amyloidosis with no evidence of systemic correlation Table $\mathbf{1}$.

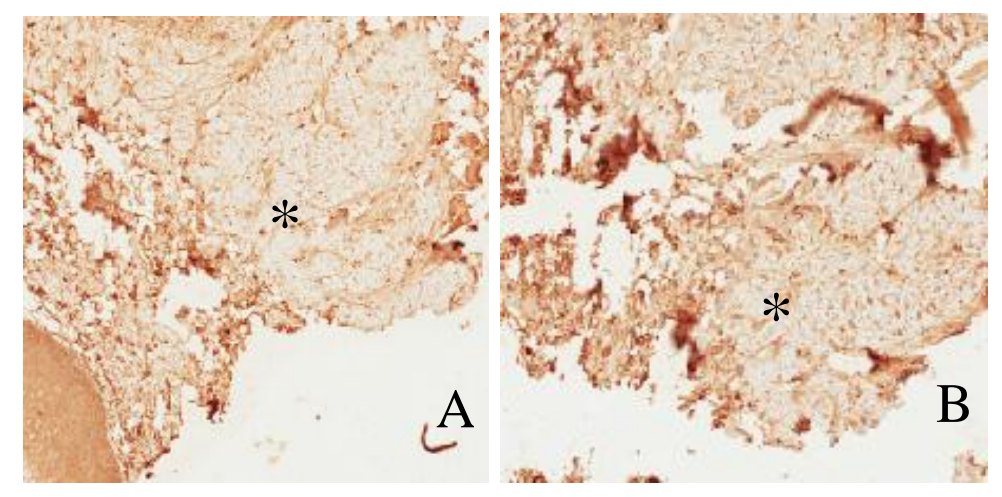

Fig. (2). (A) Lambda light chain-positive (*,20X) and (B) pre-albumin-positive (*, 20X) immunohistochemistry for case number 9.

\section{DISCUSSION}

In this retrospective study, we performed immunostaining with a panel of antibodies specific for various precursor amyloid proteins in order to detect the onset of the early systemic phase of amyloidosis and the extent of organ involvement in thirteen patients diagnosed with oral amyloidosis. The biopsy and immunostaining results were correlated with the medical history of the patients to derive a relationship between the findings of immunostainingbased immunophenotyping and the possibility of developing systemic amyloidosis. Given that the pathogenesis of amyloidosis is unclear, it is possible that amyloids are either synthesized on-site or might leak from blood vessels to accumulate at the site of deposition (the oral cavity in this case). We observed that women were more commonly affected than men and that the tongue was the most common location of amyloidosis, unlike the findings of Stoopler $e t$ al., who reported that intraoral amyloid deposits were most commonly found in the buccal mucosa [3]. However, our findings are consistent with those of Matsuo et al., who found that oral amyloidosis occurred most commonly in the tongue and among women in their study [16]. The immunophenotyping results of two patients in the present study showed an association with multiple myeloma and arthritis-related senile amyloidosis, whereas those of other patients showed localized amyloidosis of the oral cavity, with no systemic correlation. However, the positive results might not indicate the presence of the disease since immunohistochemistry may be used for typing amyloidosis but cannot be used to confirm the underlying condition.

Accurate and rapid diagnosis of amyloidosis is mandatory to avoid complication of underlying conditions and to determine if the disease is systemic and to decide the appropriate management. Localized oral amyloidosis is usually associated with inflammatory processes of infectious diseases and can be treated surgically without further consequences [17]. The specialist of oral medicine or surgery should collaborate with medical disciplines to plan a diagnostic workup for oral amyloidosis patients [18].

Existing diagnostic methods for amyloidosis are varied and unreliable. Manabe et al., used Liquid ChromatographyMass Spectrometry (LC/MS) to detect IgG heavy-chain $\lambda$ monoclonal gammopathy in a patient with rare IgG HeavyChain Amyloidosis (AH) who exhibited negative results for renal-tissue IgG immunostaining [19]. The same truncated heavy chain was identified upon LC/MS of a protein isolated from the patient's serum, which suggested that the truncated serum protein was an indication of the amyloid protein and that LC/MS is a reliable diagnostic apparatus for renal AH. However, this approach is cost-, technology- and skill-intensive and, therefore, might not be amenable for regular clinical use.

Immunostaining has been the method of choice for early detection of different forms of amyloidosis, which helps in assessing the prognosis and therapeutic protocol for the disease. For example, in a previous study, Familial Amyloid Polyneuropathy (FAP) in the vitreous was diagnosed by immunostaining Congo-red-negative biopsy samples of the vitreous with specific antibodies, indicating that early onset of FAP can be detected in patients with negative systemic tissue-biopsy results or ocular involvement [20]. Recently, Hahn et al., used a fluorescent amyloid tag, h-FTAA 
(heptamer Formyl Thiophene Acetic Acid; an anti-TTR antibody), and Congo red to recognize TTR amyloid proteins in carpal-tunnel syndrome; the authors observed that h-FTAA fluorescence and TTR immunostaining were superior to Congo red staining for positive diagnosis of ATTR [21].

Multiparameter Flow Cytometry (MFC) is another approach used for distinguishing different types of amyloidosis and determining the prognosis. Paiva et al., observed that MFC immunophenotyping of monoclonal plasma cells could be useful for distinguishing AL from other forms of amyloidosis and that patients with a relatively high number of normal plasma cells had a relatively long overall survival duration [13]. Muchtar et al., used MFC to determine the monotypic-to-polytypic plasma-cell ratio in patients with AL and correlated it with overall survival and progressionfree survival durations, showing that MFC-immunophenotyping is a useful clinical tool for assessing disease prognosis [15]. However, to the best of our knowledge, no study has attempted to distinguish different types of amyloidosis on the basis of immunostaining findings or to use the immunophenotype of localized oral amyloids as an indicator for systemic disease. Therefore, our study provides a potential approach for analyzing the possibility of detecting systemic amyloidosis in patients with solitary forms of the disease.

Nevertheless, the results of immunohistochemical staining are frequently imprecise. On the other hand, the findings of immunogold electron microscopy are accurate, depending on serological findings. Advances in diagnostic testing, such as MFC and radioactive-tracer (99 $\mathrm{m}$ technetium phosphate or aprotinin) imaging [22, 23], can help identify the type of amyloidosis with high reliability and accuracy. In fact, $99 \mathrm{~m}$ Tc phosphate can distinguish between ATTR and AL in cardiac tissues [21]. Our study is also limited by the number of biopsy specimens used. Future studies should be performed with a larger cohort of patients for more reliable results.

\section{CONCLUSION}

Immunophenotyping of oral amyloidosis can be helpful for early detection of the underlying systemic disease and/or malignancy. In our study, we detected a correlation between the immunophenotyping results of localized oral forms of amyloidosis and the underlying systemic disease in two cases. However, additional studies and accurate diagnostic tests are warranted to further support oral amyloidosis as a potential indicator of the presence of systemic disease or underlying malignancy.

\section{LIST OF ABBREVIATIONS}

$\begin{array}{lll}\text { AH } & = & \text { Immunoglobulin Heavy-chain Amyloidosis } \\ \text { AL } & = & \text { Immunoglobulin Light-chain Amyloidosis } \\ \text { ATTR } & = & \text { Transthyretin-Related Amyloidosis } \\ \text { FAP } & = & \text { Familial Amyloid Polyneuropathy } \\ \text { h-FTAA } & = & \text { heptamer Formyl Thiophene Acetic Acid } \\ \text { IGg } & = & \text { Immunoglobulin } \\ \text { LC/MS } & = & \text { Liquid Chromatography/Mass Spectrometry } \\ \text { MFC } & = & \text { Multiparameter Flow Cytometry } \\ \text { PBS } & = & \text { Phosphate Buffered Saline } \\ \text { Tc } & = & \text { Technetium } \\ \text { TTR } & = & \text { Transthyretin }\end{array}$

\section{AUTHORS' CONTRIBUTIONS}

$\mathrm{NB}, \mathrm{CI}$, and RC participated in reviewing and extracting the data. NB and RC reviewed the slides and confirmed the diagnosis. CI, SA, NB, and AS analyzed the data. NB, SA, and TM wrote the manuscript. All authors approved the final manuscript.

\section{AVAILABILITY OF DATA AND MATERIAL}

The datasets analyzed during the current study are available from the corresponding author on request.

\section{ETHICS APPROVAL AND CONSENT TO PARTICIPATE}

The study protocol was reviewed and approved by the University of Maryland Institutional Review Board (Protocol \#HP-00040308). 


\section{HUMAN AND ANIMAL RIGHTS}

No animals were used in this research. All research procedures followed were in accordance with the ethical standards of the committee responsible for human experimentation (institutional and national), and with the Helsinki Declaration of 1975, as revised in 2008 (http://www.wma.net/en/20activities/10ethics/10helsinki/).

\section{CONSENT FOR PUBLICATION}

Informed consent was obtained from the participants prior to being enrolled in the study.

\section{CONFLICT OF INTEREST}

The authors declare no conflict of interest, financial or otherwise.

\section{ACKNOWLEDGEMENTS}

The authors would like to dedicate the work to the deceased Dr. Mark Scheper.

\section{REFERENCES}

[1] Sipe JD, Benson MD, Buxbaum JN, et al. Nomenclature 2014: Amyloid fibril proteins and clinical classification of the amyloidosis. Amyloid 2014; 21(4): 221-4. [http://dx.doi.org/10.3109/13506129.2014.964858] [PMID: 25263598]

[2] Cohen AD, Comenzo RL. Systemic light-chain amyloidosis: Advances in diagnosis, prognosis, and therapy. Hematology (Am Soc Hematol Educ Program) 2010; 2010: 287-94.

[http://dx.doi.org/10.1182/asheducation-2010.1.287] [PMID: 21239808]

[3] Stoopler ET, Sollecito TP, Chen SY. Amyloid deposition in the oral cavity: A retrospective study and review of the literature. Oral Surg Oral Med Oral Pathol Oral Radiol Endod 2003; 95(6): 674-80. [http://dx.doi.org/10.1067/moe.2003.136] [PMID: 12789147]

[4] Lachmann HJ, Goodman HJ, Gilbertson JA, et al. Natural history and outcome in systemic AA amyloidosis. N Engl J Med 2007; 356(23): 2361-71. [http://dx.doi.org/10.1056/NEJMoa070265] [PMID: 17554117]

[5] Picken MM. Amyloidosis-where are we now and where are we heading? Arch Pathol Lab Med 2010; 134(4): 545-51. [PMID: 20367306]

[6] Parmar H, Rath T, Castillo M, Gandhi D. Imaging of focal amyloid depositions in the head, neck, and spine: Amyloidoma. AJNR Am J Neuroradiol 2010; 31(7): 1165-70. [http://dx.doi.org/10.3174/ajnr.A1977] [PMID: 20075086]

[7] Sekijima Y. Transthyretin (ATTR) amyloidosis: Clinical spectrum, molecular pathogenesis and disease-modifying treatments. J Neurol Neurosurg Psychiatry 2015; 86(9): 1036-43. [http://dx.doi.org/10.1136/jnnp-2014-308724] [PMID: 25604431]

[8] Coetzee GA, Strachan AF, van der Westhuyzen DR, Hoppe HC, Jeenah MS, de Beer FC. Serum amyloid A-containing human high density lipoprotein 3. Density, size, and apolipoprotein composition. J Biol Chem 1986; 261(21): 9644-51. [PMID: 3525531]

[9] Benditt EP, Eriksen N. Chemical classes of amyloid substance. Am J Pathol 1971; 65(1): 231-52. [PMID: 5096367]

[10] Picken MM. New insights into systemic amyloidosis: The importance of diagnosis of specific type. Curr Opin Nephrol Hypertens 2007; 16(3): 196-203. [http://dx.doi.org/10.1097/MNH.0b013e3280bdc0db] [PMID: 17420662]

[11] Gras SL, Waddington LJ, Goldie KN. Transmission electron microscopy of amyloid fibrils. Methods Mol Biol 2011; 752: $197-214$. [http://dx.doi.org/10.1007/978-1-60327-223-0_13] [PMID: 21713639]

[12] Deshmukh M, Elderfield K, Rahemtulla A, Naresh KN. Immunophenotype of neoplastic plasma cells in AL amyloidosis. J Clin Pathol 2009; 62(8): 724-30.

[http://dx.doi.org/10.1136/jcp.2009.065474] [PMID: 19638544]

[13] Paiva B, Vídriales MB, Pérez JJ, et al. The clinical utility and prognostic value of multiparameter flow cytometry immunophenotyping in light-chain amyloidosis. Blood 2011; 117(13): 3613-6. [http://dx.doi.org/10.1182/blood-2010-12-324665] [PMID: 21266717]

[14] Hu Y, Wang M, Chen Y, et al. Immunophenotypic analysis of abnormal plasma cell clones in bone marrow of primary systemic light chain amyloidosis patients. Chin Med J (Engl) 2014; 127(15): 2765-70. [PMID: 25146610]

[15] Muchtar E, Jevremovic D, Dispenzieri A, et al. The prognostic value of multiparametric flow cytometry in aL amyloidosis at diagnosis and at 
the end of first-line treatment. Blood 2017; 129(1): 82-7.

[http://dx.doi.org/10.1182/blood-2016-06-721878] [PMID: 27729322]

[16] Matsuo FS, Barbosa de Paulo LF, Servato JP, de Faria PR, Cardoso SV, Loyola AM. Involvement of oral tissues by AL amyloidosis: A literature review and report of eight new cases. Clin Oral Investig 2016; 20(8): 1913-20. [http://dx.doi.org/10.1007/s00784-015-1649-3] [PMID: 26556575]

[17] Shimojima Y, Matsuda M, Gono T, et al. Correlation between serum levels of free light chain and phenotype of plasma cells in bone marrow in primary AL amyloidosis. Amyloid 2005; 12(1): 33-40. [http://dx.doi.org/10.1080/02772240500032515] [PMID: 16076609]

[18] Deng J, Chen Q, Ji P, Zeng X, Jin X. Oral amyloidosis: A strategy to differentiate systemic amyloidosis involving the oral cavity and localized amyloidosis. Oral Dis 2018; 00: 16. [PMID: 29667278]

[19] Manabe S, Hatano M, Yazaki M, Nitta K, Nagata M. Renal AH amyloidosis associated with a truncated immunoglobulin heavy chain undetectable by immunostaining. Am J Kidney Dis 2015; 66(6): 1095-100. [http://dx.doi.org/10.1053/j.ajkd.2015.08.016] [PMID: 26362695]

[20] Latasiewicz M, Adan A, Solé M. Immunostaining images of vitreous transthyretin amyloid. Can J Ophthalmol 2015; 50(5): 384-7. [http://dx.doi.org/10.1016/j.jcjo.2015.06.007] [PMID: 26455975]

[21] Hahn K, Nilsson KPR, Hammarström P, et al. Establishing and validating the fluorescent amyloid ligand h-FTAA (heptamer formyl thiophene acetic acid) to identify transthyretin amyloid deposits in carpal tunnel syndrome. Amyloid 2017; 24(2): $78-86$. [http://dx.doi.org/10.1080/13506129.2017.1316711] [PMID: 28434259]

[22] Ishii S, Kubota K, Minamimoto R, et al. Lung amyloid nodule detected by 99 m Tc-aprotinin scintigraphy. Ann Nucl Med 2012 ; $26(6)$ : 522-6. [http://dx.doi.org/10.1007/s12149-012-0606-3] [PMID: 22610387]

[23] Aljaroudi WA, Desai MY, Tang WH, Phelan D, Cerqueira MD, Jaber WA. Role of imaging in the diagnosis and management of patients with cardiac amyloidosis: state of the art review and focus on emerging nuclear techniques. J Nucl Cardiol 2014; $21(2): 271-83$. [http://dx.doi.org/10.1007/s12350-013-9800-5] [PMID: 24347127]

(C) 2018 Binmadi et al.

This is an open access article distributed under the terms of the Creative Commons Attribution 4.0 International Public License (CC-BY 4.0), a copy of which is available at: https://creativecommons.org/licenses/by/4.0/legalcode. This license permits unrestricted use, distribution, and reproduction in any medium, provided the original author and source are credited. 